\title{
Optimal body mass index for minimizing the risk for osteoporosis and type 2 diabetes
}

\author{
Ji Hyun Lee ${ }^{1,2}$, Jung Hee Kim ${ }^{1}$, A Ram Hong ${ }^{1}$, Sang Wan Kim, ${ }^{1,3}$ and Chan Soo Shin ${ }^{1}$
}

Department of Internal Medicine, ${ }^{1}$ Seoul National University College of Medicine, Seoul; ${ }^{2} \mathrm{VHS}$ Medical Center, Seoul; ${ }^{3}$ Seoul Metropolitan Government Seoul National University Boramae Medical Center, Seoul, Korea

Received: June 22, 2018 Revised : September 21, 2018 Accepted: October 1, 2018

\section{Correspondence to}

Jung Hee Kim, M.D.

Department of Internal

Medicine, Seoul National

University College of Medicine,

101 Daehak-ro, Jongno-gu, Seoul 03080, Korea

Tel: +82-2-2072-4839

Fax: +82-2-764-2199

E-mail:jhkxingfu@gmail.com
Background/Aims: Body mass index (BMI) is positively associated with bone mineral density and type 2 diabetes. We investigated an optimal BMI range for osteoporosis and type 2 diabetes.

Methods: This cross-sectional study used data from the Korea National Health and Nutrition Examination Survey (KNHANES), 2008 to 2011. We included 3,774 men aged $>50$ years and 4,982 postmenopausal women. Logistic regression models were applied to elucidate each BMI category's osteoporosis and diabetes risks.

Results: The prevalence of osteoporosis was $9.0 \%$ for men and $40.8 \%$ for women. The prevalence of type 2 diabetes in men was $19.7 \%$ and in women was $15.5 \%$. In men with BMI $>25 \mathrm{~kg} / \mathrm{m}^{2}$, the osteoporosis risk did not further increase as BMI increased. In women, BMI was linearly associated with osteoporosis risk without a plateau. In both men and women, higher BMI was associated with a higher type 2 diabetes risk. Men with a BMI of 23.0 to $24.9 \mathrm{~kg} / \mathrm{m}^{2}$ harbored about a $30 \%$ lower osteoporosis risk than and a similar diabetes risk to those with a BMI of 21.0 to $22.9 \mathrm{~kg} / \mathrm{m}^{2}$. In women with a BMI of 23.0 to $24.9 \mathrm{~kg} / \mathrm{m}^{2}$, the adjusted odds ratio for osteoporosis was 0.72 ( $95 \%$ confidence interval, 0.59 to 0.87 ); the diabetes risk was not higher than in those with a BMI of 21.0 to $22.9 \mathrm{~kg} / \mathrm{m}^{2}$.

Conclusions: For Korean men aged $>50$ years and postmenopausal women, a BMI of 23.0 to $24.9 \mathrm{~kg} / \mathrm{m}^{2}$ was the optimal range for minimizing osteoporosis and type 2 diabetes risks simultaneously.

Keywords: Osteoporosis; Diabetes mellitus, type 2; Body mass index; Obesity

\section{INTRODUCTION}

Obesity is defined by excessive body fat accumulation and is a major cause of co-morbidities, such as type 2 diabetes and cardiovascular disease [1]. Weight loss remains the primary strategy for reducing the risks associated with obesity. However, several studies have shown a positive association between body mass index (BMI) and bone mineral density (BMD), and low body weight and substantial sudden weight loss induce bone loss [2]. Osteoporosis is characterized by reduced bone mass and disruption of bone architecture, resulting in increased risk of fractures. Osteoporotic fractures are associated with substantial pain and suffering, disability, and even death in affected patients and with substantial costs to the society [3]. Type 2 diabetes is associated with an increased prevalence of cardiovascular disease, causing significant morbidity and mortality [4-6]. In patients with diabetes, the risk of a wide range of vascular diseases is about twice that of patients without diabetes [7]. Therefore, it is important to minimize the risks of osteoporosis and type 2 diabetes, considering epidemics and economic consequences of the two diseases. Low body weight is a well-known risk factor for osteoporosis, but 
obesity is a significant risk factor for type 2 diabetes.

The World Health Organization (WHO) recommends the use of BMI $\geq 25 \mathrm{~kg} / \mathrm{m}^{2}$ and $\mathrm{BMI} \geq 30 \mathrm{~kg} / \mathrm{m}^{2}$ for the definitions of overweight and obese, respectively [8]. These cut-off points are based on studies of associations between BMI and increased risk of type 2 diabetes and cardiovascular disease in Western populations. Therefore, it is uncertain whether the BMI cut-off values can be applied to populations of Asian ethnicity. The WHO/ International Association for the Study of Obesity/International Obesity Task Force have proposed BMI cut-off values of 23.0 to $24.9 \mathrm{~kg} / \mathrm{m}^{2}$ for the classification of overweight and of $\geq 25.0 \mathrm{~kg} / \mathrm{m}^{2}$ for obesity in Asians [9]. In these patients, inappropriate weight loss may increase the risk of osteoporosis.

Given that BMI is the target for weight control for health in underweight or overweight adults, we investigated the optimal BMI for minimizing the risk of both osteoporosis and type 2 diabetes in the Asian population.

\section{METHODS}

\section{Subjects and study design}

This study was based on data obtained from the Korea National Health and Nutrition Examination Survey (KNHANES) IV to V (2008 to 2011). The KNHANES was a nationwide cross-sectional survey conducted in 1998 to 2012 by the Korea Centers for Disease Control and Prevention. A stratified, multistage, clustered probability design was used to select a representative sample of non-institutionalized Korean civilians for the KNHANES, which is performed periodically to estimate the health and nutritional status of the Korean population. Subjects completed a questionnaire that comprised a health interview, health examination, and nutrition survey. Detailed information regarding data collection is available on the KNHANES website (https://knhanescdcgokr/knhanes/indexdo) [10]. A total of 19,315 subjects aged $\geq 19$ years were examined between January 2008 and December 2011. Of these subjects, 9,740 were excluded because they were aged $<50$ years or were premenopausal women. Menopause was defined by a self-questionnaire as the absence of menstruation for 12 consecutive months. Moreover, 660 subjects were excluded due to missing a whole-body, dual-energy, X-ray absorptiometry (DXA) scan, and 150 subjects were excluded due to missing anthropometric data or health questionnaire survey responses. As there are no variables in the KNHANES that identify the type of diabetes, subjects who were younger than 29 years at diagnosis were assumed to have type 1 diabetes based on a previous national study of the epidemiological characteristics of diabetes in Korea [11]. Finally, 3,774 men and 4,982 women were included in the study analysis (Supplementary Fig. 1).

\section{Health behaviors and comorbidity}

Current smokers were defined as those who had smoked 100 cigarettes in their lifetime and had smoked in the last 30 days. Alcohol consumption was indicated as "yes" if the subjects drank alcohol at least once a month in the past year. The level of physical activity was evaluated using the International Physical Activity Questionnaire by WHO. Subjects classified in the moderate- and/or vigorous-intensity physical activity category engaged in moderate-intensity physical activity for at least $30 \mathrm{~min}$ utes more than five times per week, or vigorous-intensity physical activity for at least 20 minutes more than three times per week [12]. Diabetes was defined as fasting blood glucose values $\geq 126 \mathrm{mmol} / \mathrm{dL}$ or hemoglobin Alc over $6.5 \%$, self-reported diabetes medication use, or a previous diagnosis of diabetes by a physician based on the interview data. Fasting glucose and hemoglobin A1c were analyzed in a central certified laboratory. Hypertension was defined as systolic blood pressure $\geq 140$ $\mathrm{mmHg}$ or diastolic blood pressure $\geq 90 \mathrm{mmHg}$, or if the patients were currently receiving antihypertensive medication, or received a previous diagnosis of hypertension by a physician. Blood pressure was manually measured by well-trained nurses using mercury sphygmomanometers (Baumanometer; W.A. Baum, Copiague, NY, USA).

\section{Measurements of anthropometric parameters and BMD}

Height and body weight were measured using standard methods while the subjects were wearing light-weight clothes. BMI was calculated as the weight divided by height squared $\left(\mathrm{kg} / \mathrm{m}^{2}\right)$. BMI values were categorized as follows: $<18.5,18.5$ to $20.9,21.0$ to $22.9,23.0$ to $24.9,25.0$ to 29.9 , and $\geq 30 \mathrm{~kg} / \mathrm{m}^{2}$. BMD values for the lumbar spine (L1 to L4), total hip, and femur neck were measured using 
Table 1. Clinical characteristics of Korean population in 2008 to 2011 Korea National Health and Nutrition Examination Survey

\begin{tabular}{|c|c|c|c|c|}
\hline Characteristic & Total & Men & Women & $p$ value \\
\hline Number & 8,756 & 3,774 & 4,982 & \\
\hline Age, yr & $63.5 \pm 9.4$ & $63.6 \pm 8.9$ & $63.5 \pm 9.7$ & 0.480 \\
\hline Height, cm & $159.0 \pm 8.8$ & $166.5 \pm 5.9$ & $153.2 \pm 5.9$ & $<0.001$ \\
\hline Weight, kg & $60.7 \pm 10.1$ & $65.7 \pm 9.7$ & $56.8 \pm 8.7$ & $<0.001$ \\
\hline Body mass index, $\mathrm{kg} / \mathrm{m}^{2}$ & $23.9 \pm 3.1$ & $23.6 \pm 3.0$ & $24.2 \pm 3.2$ & $<0.001$ \\
\hline Current smoking & $1,465(16.7)$ & $1,238(32.8)$ & $227(4 \cdot 6)$ & $<0.001$ \\
\hline Alcohol consumption & $3,707(42.3)$ & $2,495(66.1)$ & $1,212(24 \cdot 3)$ & $<0.001$ \\
\hline Moderate- and/or vigorous-intensity PA & $2,051(23.4)$ & $961(25 \cdot 5)$ & $1,090(21.9)$ & $<0.001$ \\
\hline Osteoporosis & $2,374(27.1)$ & $339(9.0)$ & $2,035(40.8)$ & $<0.001$ \\
\hline Diabetes mellitus & $1,514(17 \cdot 3)$ & $742(19 \cdot 7)$ & $772(15 \cdot 5)$ & $<0.001$ \\
\hline Hypertension & $3,989(45.6)$ & $1,520(40.3)$ & $2,469(49.6)$ & $<0.001$ \\
\hline
\end{tabular}

Values are presented as mean \pm SD or number (\%). Differences were tested with chi-square for categorical data and with analysis of covariance for numerical data.

PA, physical activity.

DXA (Discovery QDR 4500; Hologic Inc., Waltham, MA, USA). The coefficients of variation for measurements of the lumbar spine, total hip, and femur neck were 1.9, 1.8, and $1.5 \%$, respectively. The prevalence of osteoporosis was defined by any BMD T score of less than -2.5 at the skeletal sites according to WHO recommendations [13]. The KNHANES data sets include whole-body DXA measurements of bone mineral content (g), total fat mass (g), and total lean mass (g).

\section{Statistical analysis}

We analyzed men and women separately. Baseline characteristics were compared across BMI categories using tests for trend associations. We used cubic splines to test nonlinearity in the associations between BMI, osteoporosis, and type 2 diabetes mellitus. Multivariate logistic regression models were used to study the odds ratios (ORs) of BMI categories for osteoporosis and type 2 diabetes mellitus adjusted for age, smoking habit, alcohol consumption habit, moderate- and/or vigorous-intensity physical activity, and history of malignancy. Normal BMI $\left(21.0\right.$ to $\left.22.9 \mathrm{~kg} / \mathrm{m}^{2}\right)$ was the reference group for all analyses. Statistical significance was defined as $p<0.05$. Statistical analyses were performed with Statistica version 12.0 (StatSoft Inc., Tulsa, OK, USA).

\section{Ethics statement}

Written informed consent was obtained from all the subjects. KNHANES was conducted after the being given ethical approval by the Institutional Review Board of the Korea Center for Disease Control and Prevention (approval number: 2008-04EXP-01-C, 2009-01CON-032C, 2010-02CON-21-C, 2011-02CON-o6C).

\section{RESULTS}

The clinical characteristics of the study subjects (men, $\mathrm{n}=3,774$; women, $\mathrm{n}=4,982$ ) are shown in Table 1 . The mean ages of men and women were $63.6 \pm 8.9$ and 63.5 \pm 9.7 years, respectively, and the mean BMIs were $23.6 \pm$ 3.0 and $24.2 \pm 3.2 \mathrm{~kg} / \mathrm{m}^{2}$, respectively. The prevalence of osteoporosis was $9.0 \%$ in men and $40.8 \%$ in women, and $19.7 \%$ of men and $15.5 \%$ of women had type 2 diabetes mellitus (both $p<0.001$ )

In men and women, $3.9 \%$ and $2.7 \%$ were underweight $\left(\mathrm{BMI}<18.5 \mathrm{~kg} / \mathrm{m}^{2}\right)$, respectively, whereas $31.9 \%$ of men and $37.3 \%$ of women were obese with BMI $>25 \mathrm{~kg} / \mathrm{m}^{2}$. Lower BMI categories were associated with older age, more common current smoking, and less prevalent type 2 diabetes and hypertension in both men and women. As the BMI increased, the prevalence of type 2 diabetes also increased: from $10.7 \%\left(\mathrm{BMI}<18.5 \mathrm{~kg} / \mathrm{m}^{2}\right)$ to $43.5 \%$ $\left(\mathrm{BMI} \geq 30 \mathrm{~kg} / \mathrm{m}^{2}\right)$ in men and $7.4 \%\left(\mathrm{BMI}<18.5 \mathrm{~kg} / \mathrm{m}^{2}\right)$ to $30.0 \%\left(\mathrm{BMI} \geq 30 \mathrm{~kg} / \mathrm{m}^{2}\right)$ in women. There was an inverse relationship with osteoporosis: from $38.3 \%$ (BMI 
Table 2. Clinical characteristics of men according to BMI category

\begin{tabular}{|c|c|c|c|c|c|c|}
\hline \multirow{3}{*}{ Characteristic } & \multicolumn{5}{|c|}{ BMI categories, $\mathrm{kg} / \mathrm{m}^{2}$} & \multirow{3}{*}{$p$ for trend } \\
\hline & \multirow{2}{*}{$\begin{array}{l}\text { Underweight } \\
\qquad(<18.5)\end{array}$} & \multirow{2}{*}{$\begin{array}{c}\text { Normal } \\
(18.5-22.9)\end{array}$} & \multicolumn{3}{|c|}{ Overweight } & \\
\hline & & & $\begin{array}{c}\text { At risk } \\
(23.0-24.9)\end{array}$ & $\begin{array}{c}\text { Moderately obese } \\
(25.0-29.9)\end{array}$ & $\begin{array}{l}\text { Severely obese } \\
\quad(\geq 30)\end{array}$ & \\
\hline Number & $149(3.9)$ & $1,407(37 \cdot 3)$ & $1,013(26.8)$ & $1,143(30.3)$ & $62(1.6)$ & \\
\hline Age, yr & $69.9 \pm 9.1$ & $65.2 \pm 9.1$ & $62.9 \pm 8.6$ & $61.5 \pm 8.2$ & $62.3 \pm 7.7$ & $<0.001$ \\
\hline Height, cm & $164.3 \pm 6.0$ & $166.3 \pm 5.9$ & $166.7 \pm 5.8$ & $166.9 \pm 5.7$ & $167.8 \pm 5.8$ & $<0.001$ \\
\hline Weight, kg & $47 \cdot 3 \pm 4 \cdot 3$ & $58.8 \pm 5.6$ & $66.9 \pm 4.9$ & $74.4 \pm 6.1$ & $88.6 \pm 6.8$ & $<0.001$ \\
\hline Current smoking & $61(40.9)$ & $523(37.2)$ & $313(30.9)$ & $329(28.8)$ & $12(19 \cdot 4)$ & $<0.001$ \\
\hline Alcohol consumption & $82(55.0)$ & $889(63.2)$ & $696(68.7)$ & $791(69.2)$ & $37(59.7)$ & $<0.001$ \\
\hline $\begin{array}{l}\text { Moderate- and/or } \\
\text { vigorous-intensity PA }\end{array}$ & $29(19 \cdot 5)$ & $336(23.9)$ & $273(26.9)$ & $305(26.7)$ & $18(29.0)$ & 0.127 \\
\hline Osteoporosis & $57(38.3)$ & $190(13.5)$ & $5^{8}(5 \cdot 7)$ & $29(2.5)$ & $5(8.1)$ & $<0.001$ \\
\hline Diabetes mellitus & $16(10.7)$ & $233(16.6)$ & $191(18.9)$ & $275(24.1)$ & $27(43 \cdot 5)$ & $<0.001$ \\
\hline Hypertension & $46(30.9)$ & $500(35.5)$ & $435(42.9)$ & $511(44.7)$ & $28(45.2)$ & $<0.001$ \\
\hline
\end{tabular}

Values are presented as number $(\%)$ or mean \pm SD. Differences were tested with chi-square for categorical data and with analysis of covariance for numerical data.

BMI, body mass index; PA, physical activity.

Table 3. Clinical characteristics of women according to BMI category

\begin{tabular}{|c|c|c|c|c|c|c|}
\hline \multirow{3}{*}{ Characteristic } & \multicolumn{5}{|c|}{ BMI categories, $\mathrm{kg} / \mathrm{m}^{2}$} & \multirow{3}{*}{$p$ for trend } \\
\hline & \multirow{2}{*}{$\begin{array}{l}\text { Underweight } \\
<18.5\end{array}$} & \multirow{2}{*}{$\begin{array}{l}\text { Normal } \\
18.5-22.9\end{array}$} & \multicolumn{3}{|c|}{ Overweight } & \\
\hline & & & $\begin{array}{c}\text { At risk } \\
(23.0-24.9)\end{array}$ & $\begin{array}{l}\text { Moderately obese } \\
(25.0-29.9)\end{array}$ & $\begin{array}{c}\text { Severely obese } \\
\quad \geq 30\end{array}$ & \\
\hline Number & $136(2.7)$ & $1,717(34 \cdot 5)$ & $1,274(25.6)$ & $1,652(33.2)$ & $203(4.1)$ & \\
\hline Age, yr & $67.6 \pm 11.9$ & $63.6 \pm 10.4$ & $62.8 \pm 9.3$ & $63.6 \pm 9.0$ & $62.7 \pm 9.5$ & $<0.001$ \\
\hline Height, cm & $152.8 \pm 6.5$ & $153 \cdot 3 \pm 6.0$ & $153.6 \pm 5.9$ & $153.1 \pm 5.7$ & $152.7 \pm 5.7$ & 0.099 \\
\hline Weight, kg & $41.0 \pm 4.1$ & $50.1 \pm 4.9$ & $56.7 \pm 4.5$ & $62.9 \pm 5.5$ & $75 \cdot 3 \pm 7.6$ & $<0.001$ \\
\hline Current smoking & $19(14.0)$ & $94(5 \cdot 5)$ & $52(4 \cdot 1)$ & $55(3 \cdot 3)$ & $7(3.4)$ & $<0.001$ \\
\hline Alcohol consumption & $20(14.7)$ & $422(24 \cdot 6)$ & $311(24.4)$ & $407(24.6)$ & $52(25.6)$ & 0.127 \\
\hline $\begin{array}{l}\text { Moderate- and/or } \\
\text { vigorous-intensity PA }\end{array}$ & $24(17.6)$ & $353(20.6)$ & $268(21.0)$ & $398(24.1)$ & $47(23.2)$ & 0.071 \\
\hline Osteoporosis & $104(76.5)$ & $844(49.2)$ & $492(38.6)$ & $55^{2}(33.4)$ & $43(21.2)$ & $<0.001$ \\
\hline Diabetes mellitus & $10(7 \cdot 4)$ & $194(11.3)$ & $186(14.6)$ & $321(19.4)$ & $61(30.0)$ & $<0.001$ \\
\hline Hypertension & $48(35 \cdot 3)$ & $691(40.2)$ & $599(47.0)$ & $980(59.3)$ & $151(74 \cdot 4)$ & $<0.001$ \\
\hline
\end{tabular}

Values are presented as number (\%) or mean \pm SD. Differences were tested with chi-square for categorical data and with analysis of covariance for numerical data.

BMI, body mass index; PA, physical activity.

$\left.<18.5 \mathrm{~kg} / \mathrm{m}^{2}\right)$ to $8.1 \%\left(\mathrm{BMI} \geq 30 \mathrm{~kg} / \mathrm{m}^{2}\right)$ in men and from $76.5 \%\left(\mathrm{BMI}<18.5 \mathrm{~kg} / \mathrm{m}^{2}\right)$ to $21.2 \%\left(\mathrm{BMI} \geq 30 \mathrm{~kg} / \mathrm{m}^{2}\right)$ in women (Tables 2 and 3, Fig. 1). As the BMI increased, the percentages fat mass increased but the percentages lean mass decreased in both men and women (both $p<$ 0.001) (Fig. 2).

In men, the relationship between BMI and osteoporosis reached a plateau around a BMI of $25 \mathrm{~kg} / \mathrm{m}^{2}$. 
However, increasing BMI was linearly associated with decreases in osteoporosis in women and was associated with increases in the prevalence of type 2 diabetes in both men and women (Fig. 3).

We further used the logistic regression models of BMI categories for the risk of osteoporosis and type 2 diabetes after adjusting for age, smoking, alcohol consumption, moderate- and/or vigorous-intensity physical activities, and history of malignancy (Table 4 and 5). Men with a BMI of $<18.5 \mathrm{~kg} / \mathrm{m}^{2}$ showed the highest risk for osteoporosis (OR, 4.95; 95\% confidence interval [CI], 3.25 to 7.54) and the lowest risk for type 2 diabetes (OR, 0.48; 95\% CI, 0.28 to 0.83$)$. In men, compared with the reference range of BMI (21.0 to $22.9 \mathrm{~kg} / \mathrm{m}^{2}$ ), a BMI of 23.0 to $24.9 \mathrm{~kg} / \mathrm{m}^{2}$ was the highest BMI category for lowering osteoporosis risk without increasing type 2 diabetes risk. Women with a $\mathrm{BMI}<18.5 \mathrm{~kg} / \mathrm{m}^{2}$ showed the highest risk for osteoporosis (OR, 3.67; 95\% CI, 2.23 to 6.05), but those with a BMI of $<18.5 \mathrm{~kg} / \mathrm{m}^{2}$ carried the lowest risk for type 2 diabetes (OR, 0.44; 95\% CI, 0.22 to 0.87). Similar to men, a BMI of 23.0 to $24.9 \mathrm{~kg} / \mathrm{m}^{2}$ was the highest BMI category for lowering osteoporosis risk without increasing type 2 diabetes risk among BMI categories.

\section{DISCUSSION}

In the nationwide study of Korean men above 50 years and postmenopausal women, we elucidated that a BMI of 23.0 to $24.9 \mathrm{~kg} / \mathrm{m}^{2}$ was the optimal range for minimizing the risk of both osteoporosis and type 2 diabetes. The associations were maintained, even after adjustments for covariates, such as smoking, alcohol consumption, physical activities, and history of malignancy.

BMI is a strong and modifiable risk factor for both osteoporosis and type 2 diabetes. Being obese and overweight are strong protectors against bone loss. Ho et al. [14] reported that body weight was the best predictor of osteoporosis in postmenopausal Chinese women. A low BMI is associated with decreased BMD, and an increased risk of osteoporosis and osteoporotic fractures $[2,15]$. Compared with a BMI of $25 \mathrm{~kg} / \mathrm{m}^{2}$, a BMI of $<20$ $\mathrm{kg} / \mathrm{m}^{2}$ had a risk ratio (RR) of about twice (RR, 1.95; $95 \%$ CI, 1.71 to 2.22) for hip fracture [16]. Optimal BMI levels

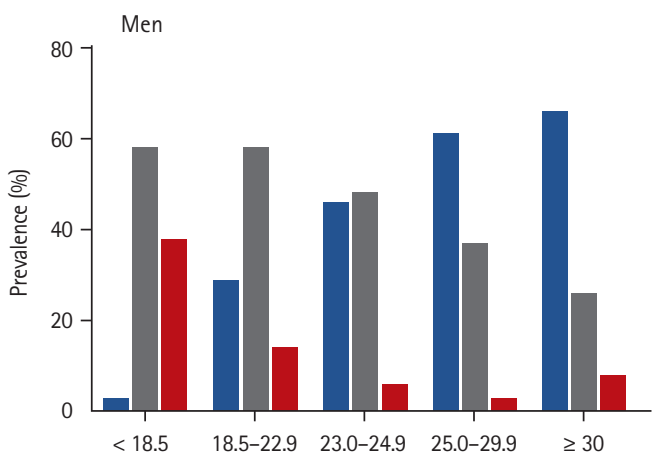

A

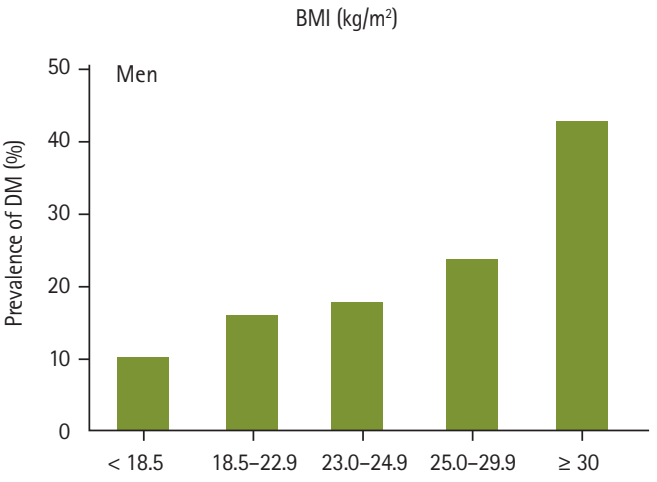

BMI $\left(\mathrm{kg} / \mathrm{m}^{2}\right)$
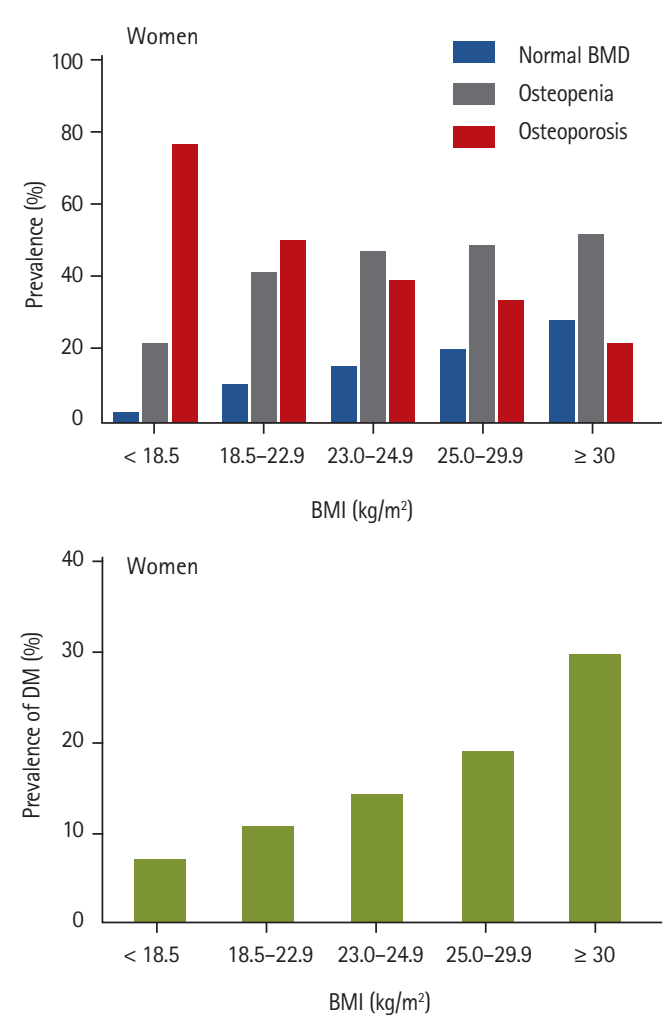

Figure 1. Prevalence of osteoporosis (A) and type 2 diabetes mellitus (B) in men and women. DM, diabetes mellitus; BMI, body mass index; BMD, bone mineral density. 


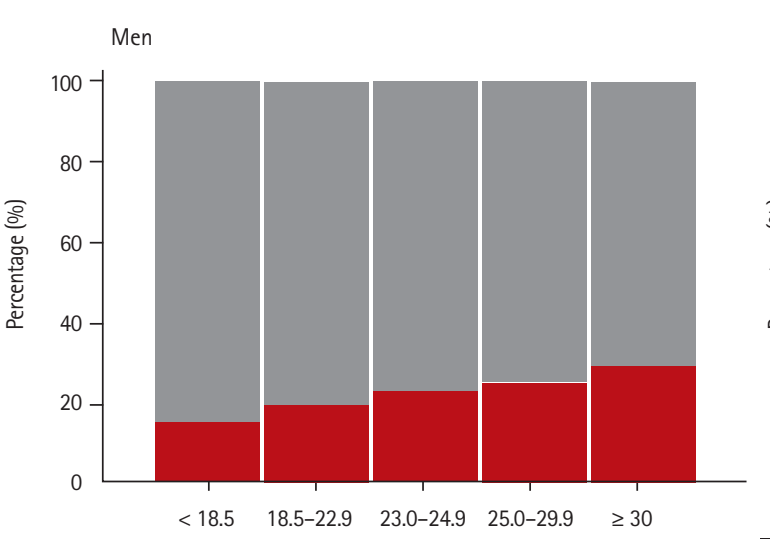

a
B

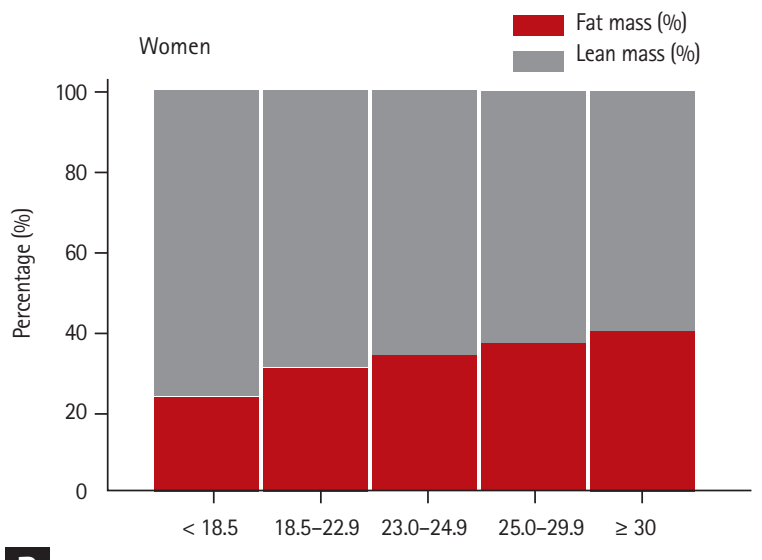

$\mathrm{BMI}\left(\mathrm{kg} / \mathrm{m}^{2}\right)$

Figure 2. Percentages fat and lean mass according to body mass index (BMI) categories. (A) Men. (B) Women.
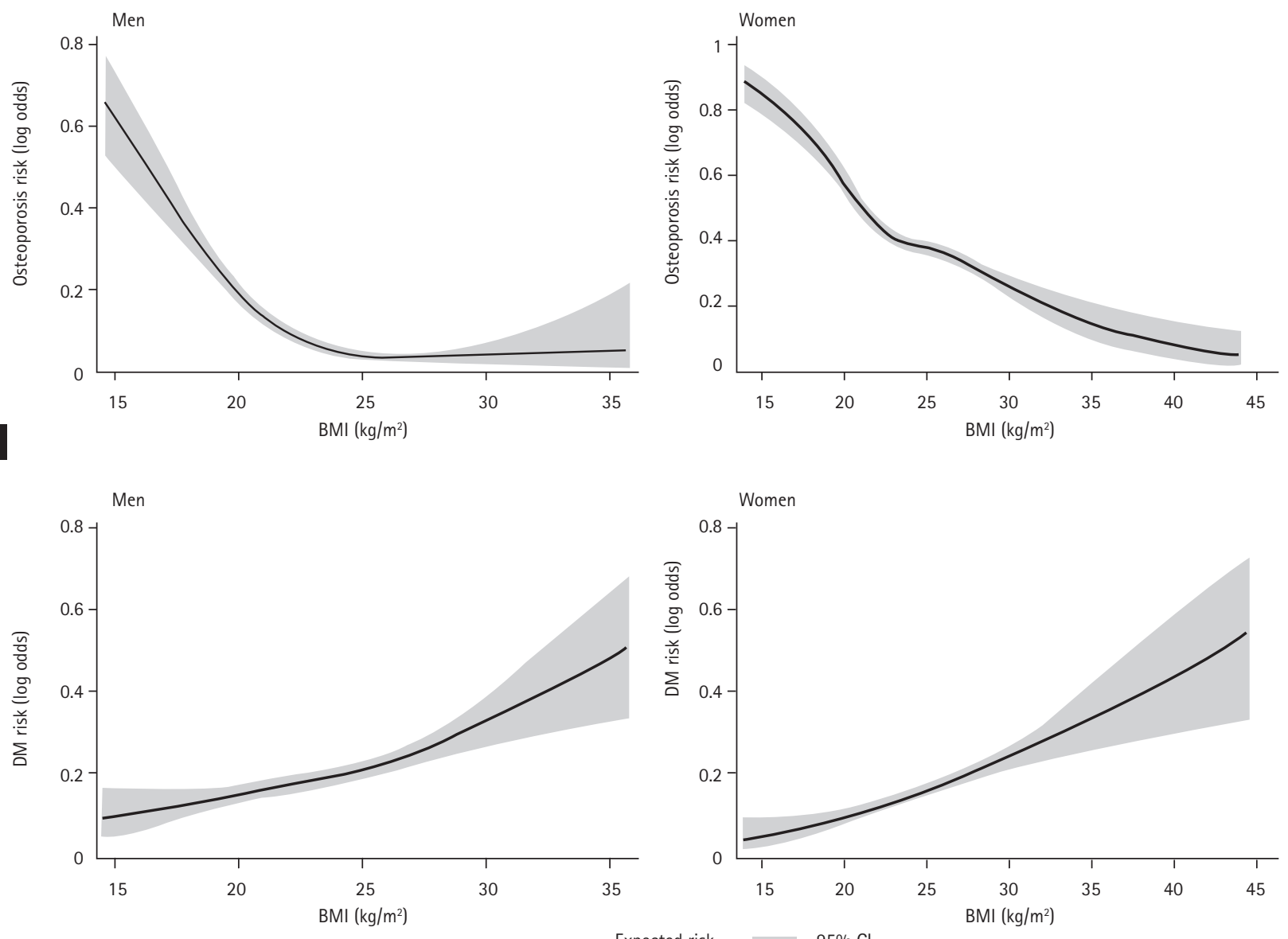

B

Figure 3. Association between body mass index (BMI) and (A) osteoporosis or (B) diabetes mellitus (DM) in men and women. CI, confidence interval. 
Table 4. Logistic regression model of BMI categories for osteoporosis and diabetes in men after adjusting for covariates

\begin{tabular}{|c|c|c|c|c|c|c|}
\hline \multirow{2}{*}{ Variable } & \multicolumn{6}{|c|}{ BMI categories, $\mathrm{kg} / \mathrm{m}^{2}$} \\
\hline & $<18.5$ & $18.5-20.9$ & $21.0-22.9$ & $23.0-24.9$ & $25.0-29.9$ & $\geq 30$ \\
\hline \multicolumn{7}{|l|}{ Osteoporosis } \\
\hline Number & 149 & 569 & 838 & 1,013 & 1,143 & 62 \\
\hline Unadjusted & $6.4(4.26-9.61)$ & $2.64(1.93-3.62)$ & 1 (ref) & $0.63(0.44-0.90)$ & $0.27(0.17-0.42)$ & $0.91(0.35-2.33)$ \\
\hline Age adjusted & $5.16(3.40-7.84)$ & $2.58(1.87-3.54)$ & 1 (ref) & $0.7(0.48-0.99)$ & $0.32(0.21-0.50)$ & $1.07(0.41-2.77)$ \\
\hline Current model $^{\mathrm{a}}$ & $4.95(3.25-7.54)$ & $2.51(1.82-3.46)$ & 1 (ref) & $0.71(0.49-1.02)$ & $0.33(0.21-0.52)$ & $1.16(0.45-3.03)$ \\
\hline \multicolumn{7}{|l|}{ Diabetes } \\
\hline Number & 149 & 569 & 838 & 1,013 & 1,143 & 62 \\
\hline Unadjusted & $0.48(0.28-0.83)$ & $0.78(0.58-1.05)$ & 1 (ref) & $1.07(0.85-1.36)$ & $1.46(1.17-1.83)$ & $3.54(2.08-6.02)$ \\
\hline Age adjusted & $0.49(0.28-0.85)$ & $0.77(0.57-1.03)$ & 1 (ref) & $1.12(0.88-1.41)$ & $1.57(1.26-1.97)$ & $3.79(2.22-6.47)$ \\
\hline Current model $^{\mathrm{a}}$ & $0.48(0.28-0.83)$ & $0.76(0.56-1.02)$ & 1 (ref) & $1.13(0.89-1.43)$ & $1.6(1.27-2.01)$ & $3.84(2.24-6.56)$ \\
\hline
\end{tabular}

Values are presented as odds ratio (95\% confidence interval).

BMI, body mass index.

${ }^{a}$ Current model was analysed using logistic regression adjusted for smoking, alcohol, moderate- and/or vigorous-intensity physical activities, and history of malignancy.

for osteoporosis are not established, although Skrzek el al. [17] reported a BMI category of 26.0 to $27.9 \mathrm{~kg} / \mathrm{m}^{2}$ for the lowest risk of osteoporosis in postmenopausal women. We demonstrated that a BMI of 25.0 to $29.9 \mathrm{~kg} / \mathrm{m}^{2}$ in men and $\geq 30 \mathrm{~kg} / \mathrm{m}^{2}$ in women conferred the lowest risk for osteoporosis. Compared with the reference group of BMI 21.0 to 22.9, the OR for osteoporosis was reduced by more than $60 \%$ in men with BMI of 25.0 to 29.9 and women with $\mathrm{BMI}$ of $\geq 30$.

On the other hand, increasing BMI by $1 \mathrm{~kg} / \mathrm{m}^{2}$ increased the risk of developing type 2 diabetes by $8.4 \%$ [18]. With this Korean data, an increase in BMI per $1 \mathrm{~kg} / \mathrm{m}^{2}$ was related with the risk of type 2 diabetes by $10 \%$ in men and $12 \%$ in women. As the BMI increase by $1 \mathrm{~kg} / \mathrm{m}^{2}$, the risk of osteoporosis in men and women decreases by $28 \%$ and $13 \%$, respectively.

Approximately $80 \%$ of individuals with type 2 diabetes are overweight or obese (http://win.niddk.nih.gov/publications/PDFs/hlthrisks1104.pdf) [19]. In prediabetes, weight loss has been shown to delay the onset or reduce the risk of type 2 diabetes, while in type 2 diabetes, it has been shown to improve glycemic control [20-22]. In Asian populations, the proposed BMI cutoff values are between 23.0 to $27.5 \mathrm{~kg} / \mathrm{m}^{2}$ for predicting the risk of type 2 diabetes, as well as cardiovascular disease and all-cause mortality [23-26]. Asian populations retain a relatively higher body fat percentage at a lower BMI than Western populations. Previous studies have shown that the risk of developing cardiovascular disease or type 2 diabetes is high at lower BMIs than that in Western populations [27]. Regarding the equivalent incidence of type 2 diabetes at a BMI of $30 \mathrm{~kg} / \mathrm{m}^{2}$ in Western populations, the BMI cutoff value was $24 \mathrm{~kg} / \mathrm{m}^{2}$ in South Asian, $25 \mathrm{~kg} / \mathrm{m}^{2}$ in Chinese, and $26 \mathrm{~kg} / \mathrm{m}^{2}$ in African populations [28]. We showed that the risk for type 2 diabetes began to increase at BMIs of $25 \mathrm{~kg} / \mathrm{m}^{2}$ in men and women, which were the opposite for osteoporosis risk. Compared to men with a BMI of 21.0 to 22.9, men with a BMI of 25 to $29.9 \mathrm{had}$ a 1.60-fold increase in type 2 diabetes risk and a $0.33-$ fold reduction in the risk of osteoporosis. Compared to women with a BMI of 21.0 to 22.9, women with a BMI of 25.0 to 29.9 increased the risk of type 2 diabetes by 1.74fold and decreased the risk of osteoporosis by 0.49 -fold.

According to a large prospective cohort study of Western populations, the BMI category associated with the lowest all-cause mortality was $22.5 \mathrm{~kg} / \mathrm{m}^{2}$ or 20.0 to 25.0 $\mathrm{kg} / \mathrm{m}^{2}$ [29,30], whereas other study has shown that the BMI category 25.0 to $29.9 \mathrm{~kg} / \mathrm{m}^{2}$ confers a lower all-cause mortality rate than the normal weight (BMI 18.5 to 24.9 $\mathrm{kg} / \mathrm{m}^{2}$ ) [31]. In Asian populations, $\mathrm{Ng}$ et al. [32] showed that the BMI exhibited a U-shaped association with allcause and cardiovascular mortality, with a nadir at BMI 
Table 5. Logistic regression model of BMI categories for osteoporosis and diabetes in women after adjusting for covariates

\begin{tabular}{|c|c|c|c|c|c|c|}
\hline \multirow{2}{*}{ Variable } & \multicolumn{6}{|c|}{ BMI categories, $\mathrm{kg} / \mathrm{m}^{2}$} \\
\hline & $<18.5$ & $18.5-20.9$ & $21.0-22.9$ & $23.0-24.9$ & $25.0-29.9$ & $\geq 30$ \\
\hline \multicolumn{7}{|l|}{ Osteoporosis } \\
\hline Number & 136 & 636 & 1,081 & 1,274 & 1,652 & 203 \\
\hline Unadjusted & $3.82(2.52-5.78)$ & $1.41(1.16-1.71)$ & $1(\mathrm{ref})$ & $0.74(0.63-0.87)$ & $0.59(0.50-0.69)$ & $0.32(0.22-0.45)$ \\
\hline Age adjusted & $3.77(2.29,6.20)$ & $1.44(1.14-1.82)$ & 1 (ref) & $0.71(0.59-0.86)$ & $0.48(0.40-0.58)$ & $0.24(0.16-0.36)$ \\
\hline Current model $^{\mathrm{a}}$ & $3.67(2.23-6.05)$ & $1.43(1.13-1.81)$ & 1 (ref) & $0.72(0.59-0.87)$ & $0.49(0.41-0.59)$ & $0.25(0.16-0.37)$ \\
\hline \multicolumn{7}{|l|}{ Diabetes } \\
\hline Number & 136 & 636 & 1,081 & 1,274 & 1,652 & 203 \\
\hline Unadjusted & $0.56(0.29-1.09)$ & $0.74(0.53-1.09)$ & 1 (ref) & $1.21\left(0.95^{-1.53)}\right.$ & $1.70(1.37-2.12)$ & $3.04(2.14-4.31)$ \\
\hline Age adjusted & $0.45(0.23-0.88)$ & $0.69(0.50-0.96)$ & 1 (ref) & $1.25(0.98-1.59)$ & $1.73(1.39-2.16)$ & $3.24(2.27-4.63)$ \\
\hline Current model $^{\mathrm{a}}$ & $0.44(0.22-0.87)$ & $0.69(0.50-0.96)$ & 1 (ref) & $1.25(0.98-1.59)$ & $1.74(1.39-2.17)$ & $3.27(2.29-4.68)$ \\
\hline
\end{tabular}

Values are presented as odds ratio ( $95 \%$ confidence interval).

BMI, body mass index.

${ }^{a}$ Current model was analysed using logistic regression adjusted for smoking, alcohol, and moderate- and/or vigorous-intensity physical activities, history of malignancy.

23.0 to $24.9 \mathrm{~kg} / \mathrm{m}^{2}$. In line with this, we also revealed that BMI of 23.0 to $24.9 \mathrm{~kg} / \mathrm{m}^{2}$ was the optimal range for minimizing the risk of both osteoporosis and type 2 diabetes.

We also observed a sexual dimorphism between BMI and osteoporosis. Unlike women, further increases of BMI over $25 \mathrm{~kg} / \mathrm{m}^{2}$ did not result in a beneficial effect on osteoporosis risk in men in this study. Pluijm et al. [33] also found that BMD is positively related to fat mass in 264 women, but not in 258 men. Discordant association between BMI and sexual hormones in men and women may partially explain our findings. Testosterone and sexual hormone binding globulin levels decreased in men with increased BMI, while a favorable association was shown between BMI and serum estrogen concentrations in postmenopausal women [34-36]. Karim et al. [35] suggested that these associations can be explained by the increased fat mass with increased peripheral aromatization after menopause. Another putative mechanism is increased plasma levels of leptin. A recent meta-analysis showed that high levels of leptin were positively associated with BMD in postmenopausal women [37].

Several caveats should be mentioned. The results of this study must be interpreted within the limits of a cross-sectional design focused on the association between BMI and comorbidities, and they were unable to explain causality. The study findings did not account for the BMI throughout childhood and young adult years of life which can be a critical determinant of osteoporosis. Also, BMI does not consider the relative proportions of fat and lean mass and cannot distinguish body fat distribution. However, higher BMI corresponded to a greater percentage fat mass and a lower percentage lean mass (Fig. 2). Because the percentage fat mass is strongly correlated with insulin resistance, a higher BMI contributes to the development of type 2 diabetes [38,39]. As BMI increases, the risk of hip fracture may decrease because of the mechanical loading effect of higher body weight, more muscle mass, and greater soft tissue padding over the hip [40]. However, fat mass has been inversely associated with BMD after adjustment for weight, suggesting that fat mass has a detrimental effect on bones [41]. Meyer et al. [42] reported that abdominal obesity was associated with an increased risk of hip fracture. Our baseline variables were collected from self-reported data. Because of the limitations of the data, we were unable to include information regarding the use of steroids. Self-reported diabetic medication use is used as a criterion to define diabetes in this study. This could potentially have overestimated the diagnosis of diabetes. However, the KNHANES is a nationwide, population-based survey of the Korean population, which provides an important basis for investigating the prevalence and associated factors of osteoporosis and type 2 diabetes in large data samples.

To our knowledge, this was the first study to demon- 
strate an appropriate BMI range for both osteoporosis and type 2 diabetes in Korean men and women. In conclusion, our findings show that a BMI of 23.0 to $24.9 \mathrm{~kg} /$ $\mathrm{m}^{2}$ is an optimal range for minimizing the risk of both osteoporosis and type 2 diabetes in Korean men over 50 years of age and postmenopausal women. Further studies on gender differences in the association between BMI and osteoporosis are warranted. Prospective longitudinal studies are also needed to validate the optimal BMI to minimize the risk of developing osteoporosis and type 2 diabetes.

\section{KEY MESSAGE}

1. For Korean men aged $>50$ years with body mass index $(\mathrm{BMI})>25 \mathrm{~kg} / \mathrm{m}^{2}$, the osteoporosis risk did not further increase as BMI increased. For postmenopausal women, BMI was linearly associated with osteoporosis risk without a plateau.

2. For Korean men aged $>50$ years and postmenopausal women, higher BMI was associated with a higher type 2 diabetes risk after covariate adjustments.

3. For Korean men aged $>50$ years and postmenopausal women, a BMI of 23.0 to $24.9 \mathrm{~kg} /$ $\mathrm{m}^{2}$, which was the classification of overweight according to the World Health Organization in Asians, was the optimal range for minimizing the risk of osteoporosis and type 2 diabetes simultaneously.

\section{Conflict of interest}

No potential conflict of interest relevant to this article was reported.

\section{REFERENCES}

1. Centers for Disease Control and Prevention. Obesity and overweight for professionals: data and statistics: adult obesity [Internet]. Atlanta (GA): Centers for Disease Control and Prevention, 2014 [cited 2019 Sep 2]. Available from: http://www.cdc.gov/obesity/data/adult.html.

2. Ravn P, Cizza G, Bjarnason NH, et al. Low body mass in- dex is an important risk factor for low bone mass and increased bone loss in early postmenopausal women. Early Postmenopausal Intervention Cohort (EPIC) study group. J Bone Miner Res 1999;14:1622-1627.

3. Hernlund E, Svedbom A, Ivergard M, et al. Osteoporosis in the European Union: medical management, epidemiology and economic burden. A report prepared in collaboration with the International Osteoporosis Foundation (IOF) and the European Federation of Pharmaceutical Industry Associations (EFPIA). Arch Osteoporos 2013;8:136.

4. Inzucchi SE, Bergenstal RM, Buse JB, et al. Management of hyperglycemia in type 2 diabetes: a patient-centered approach: position statement of the American Diabetes Association (ADA) and the European Association for the Study of Diabetes (EASD). Diabetes Care 2012;35:1364-1379.

5. Roper NA, Bilous RW, Kelly WF, Unwin NC, Connolly VM; South Tees Diabetes Mortality Study. Cause-specific mortality in a population with diabetes: South Tees Diabetes Mortality Study. Diabetes Care 2002;25:43-48.

6. Rao Kondapally Seshasai S, Kaptoge S, Thompson A, et al. Diabetes mellitus, fasting glucose, and risk of cause-specific death. N Engl J Med 2011;364:829-841.

7. Emerging Risk Factors Collaboration, Sarwar N, Gao P, et al. Diabetes mellitus, fasting blood glucose concentration, and risk of vascular disease: a collaborative meta-analysis of 102 prospective studies. Lancet 2010;375:2215-2222.

8. World Health Organization. Physical Status: the Use and Interpretation of Anthropometry: Report of a WHO Expert Committee. Geneva (CH): World Health Organization, 1995 .

9. World Health Organization, International Association for the Study of Obesity, International Obesity Task Force. The Asia-Pacific perspective: redefining obesity and its treatment [Internet]. Geneva (CH): World Health Organization, c2017 [cited 2019 Sep 2]. Available from: https:// www.who.int/.

10. Korea Centers for Disease Control and Prevention. Korean National Health and Nutrition Examination Survey (KNHANES) [Internet]. Cheongju (KR): Korea Centers for Disease Control and Prevention, 2011 [cited 2019 Sep 2]. Available from: https://knhanes.cdc.go.kr/knhanes/indexdo.

11. Park JH, Lee YE. Effects of exercise on glycemic control in type 2 diabetes mellitus in Koreans: the fifth Korea National Health and Nutrition Examination Survey (KNHANES V). J Phys Ther Sci 2015;27:3559-3564. 
12. Hootman JM, Macera CA, Ham SA, Helmick CG, Sniezek JE. Physical activity levels among the general US adult population and in adults with and without arthritis. Arthritis Rheum 2003;49:129-135.

13. Genant HK, Cooper C, Poor G, et al. Interim report and recommendations of the World Health Organization Task-Force for Osteoporosis. Osteoporos Int 1999;10:259264.

14. Ho SC, Chen YM, Woo JL. Educational level and osteoporosis risk in postmenopausal Chinese women. Am J Epidemiol 2005;161:680-690.

15. Espallargues M, Sampietro-Colom L, Estrada MD, et al. Identifying bone-mass-related risk factors for fracture to guide bone densitometry measurements: a systematic review of the literature. Osteoporos Int 2001;12:811-822.

16. De Laet C, Kanis JA, Oden A, et al. Body mass index as a predictor of fracture risk: a meta-analysis. Osteoporos Int 2005;16:1330-1338.

17. Skrzek A, Koziel S, Ignasiak Z. The optimal value of BMI for the lowest risk of osteoporosis in postmenopausal women aged 40-88 years. Homo 2014;65:232-239.

18. Bombelli M, Facchetti R, Sega R, et al. Impact of body mass index and waist circumference on the long-term risk of diabetes mellitus, hypertension, and cardiac organ damage. Hypertension 2011;58:1029-1035.

19. National Institutes of Health, National Institute of Diabetes, \& Digestive and Kidney Disease. Do you know some of the health risks of being overweight? NIH Publication No. 07-4098 [Internet]. Bethesda (MD): National Institutes of Health, 2004 [cited 2019 Sep 2]. Available from: http:// www.nwtcc.com/assets/obesity.pdf.

20. Pan XR, Li GW, Hu YH, et al. Effects of diet and exercise in preventing NIDDM in people with impaired glucose tolerance. The Da Qing IGT and Diabetes Study. Diabetes Care 1997;20:537-544.

21. Knowler WC, Barrett-Connor E, Fowler SE, et al. Reduction in the incidence of type 2 diabetes with lifestyle intervention or metformin. N Engl J Med 2002;346:393-403.

22. Lindstrom J, Louheranta A, Mannelin M, et al. The Finnish Diabetes Prevention Study (DPS): lifestyle intervention and 3-year results on diet and physical activity. Diabetes Care 2003;26:3230-3236.

23. Gu D, He J, Duan X, et al. Body weight and mortality among men and women in China. JAMA 2006;295:776783.

24. Lyall DM, Celis-Morales C, Ward J, et al. Association of body mass index with cardiometabolic disease in the UK Biobank: a Mendelian randomization study. JAMA Cardiol 2017;2:882-889.

25. Zheng W, McLerran DF, Rolland B, et al. Association between body-mass index and risk of death in more than 1 million Asians. N Engl J Med 2011;364:719-729.

26. Kong KA, Park J, Hong SH, et al. Associations between body mass index and mortality or cardiovascular events in a general Korean population. PLoS One 2017;12:e0185024.

27. Deurenberg-Yap M, Deurenberg P. Is a re-evaluation of WHO body mass index cut-off values needed? The case of Asians in Singapore. Nutr Rev 2003;61(5 Pt 2):S80-S87.

28. Chiu M, Austin PC, Manuel DG, Shah BR, Tu JV. Deriving ethnic-specific BMI cutoff points for assessing diabetes risk. Diabetes Care 2011;34:1741-1748.

29. Prospective Studies Collaboration, Whitlock G, Lewington $\mathrm{S}$, et al. Body-mass index and cause-specific mortality in 900 ooo adults: collaborative analyses of 57 prospective studies. Lancet 2009;373:1083-1096.

30. Berrington de Gonzalez A, Hartge P, Cerhan JR, et al. Body-mass index and mortality among 1.46 million white adults. N Engl J Med 2010;363:2211-2219.

31. Flegal KM, Kit BK, Orpana H, Graubard BI. Association of all-cause mortality with overweight and obesity using standard body mass index categories: a systematic review and meta-analysis. JAMA 2013;309:71-82.

32. Ng TP, Jin A, Chow KY, Feng L, Nyunt MSZ, Yap KB. Age-dependent relationships between body mass index and mortality: Singapore longitudinal ageing study. PLoS One 2017;12:e0180818.

33. Pluijm SM, Visser M, Smit JH, Popp-Snijders C, Roos JC, Lips P. Determinants of bone mineral density in older men and women: body composition as mediator. J Bone Miner Res 2001;16:2142-2151.

34. Zumoff B, Strain GW, Miller LK, et al. Plasma free and non-sex-hormone-binding-globulin-bound testosterone are decreased in obese men in proportion to their degree of obesity. J Clin Endocrinol Metab 1990;71:929-931.

35. Karim R, Mack WJ, Hodis HN, Roy S, Stanczyk FZ. Influence of age and obesity on serum estradiol, estrone, and sex hormone binding globulin concentrations following oral estrogen administration in postmenopausal women. J Clin Endocrinol Metab 2009;94:4136-4143.

36. Osuna JA, Gomez-Perez R, Arata-Bellabarba G, Villaroel V. Relationship between BMI, total testosterone, sex hormone-binding-globulin, leptin, insulin and insulin resis- 
tance in obese men. Arch Androl 2006;52:355-361.

37. Biver E, Salliot C, Combescure C, et al. Influence of adipokines and ghrelin on bone mineral density and fracture risk: a systematic review and meta-analysis. J Clin Endocrinol Metab 2011;96:2703-2713.

38. Kurniawan LB, Bahrun U, Hatta M, Arif M. Body mass, total body fat percentage, and visceral fat level predict insulin resistance better than waist circumference and body mass index in healthy young male adults in Indonesia. J Clin Med 2018;7:E96.

39. Gomez-Ambrosi J, Silva C, Galofre JC, et al. Body adiposity and type 2 diabetes: increased risk with a high body fat percentage even having a normal BMI. Obesity (Silver Spring) 2011;19:1439-1444.

40. Shapses SA, Sukumar D. Bone metabolism in obesity and weight loss. Annu Rev Nutr 2012;32:287-309.

41. Zhao LJ, Liu YJ, Liu PY, Hamilton J, Recker RR, Deng HW. Relationship of obesity with osteoporosis. J Clin Endocrinol Metab 2007;92:1640-1646.

42. Meyer HE, Willett WC, Flint AJ, Feskanich D. Abdominal obesity and hip fracture: results from the Nurses' Health Study and the Health Professionals Follow-up Study. Osteoporos Int 2016;27:2127-2136. 


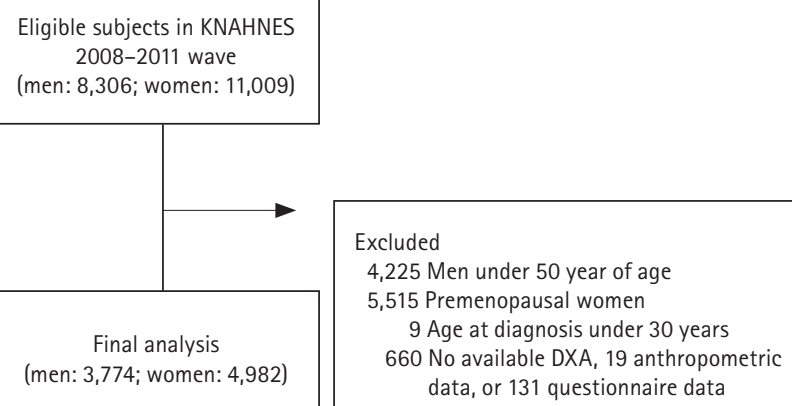

Final analysis

(men: 3,774; women: 4,982)

Excluded

4,225 Men under 50 year of age

5,515 Premenopausal women

9 Age at diagnosis under 30 years

660 No available DXA, 19 anthropometric

data, or 131 questionnaire data

Supplementary Figure 1. Flow diagram of study subjects. KNAHNES, Korean National Health and Nutrition Examination Survey. DXA, dual-energy, X-ray absorptiometry. 